\title{
Upaya Peningkatan Jumlah Usaha Rintisan melalui Program Pengembangan Kewirausahaan
}

\author{
Adhi Kusnadi $^{*}$, Wella ${ }^{1}$ dan Rangga Winantyo ${ }^{1}$ \\ ${ }^{1}$ Fakultas Teknik dan Informatika, Universitas Multimedia Nusantara, Jl. Scientia Boulevard Gading \\ Serpong, Tangerang, Indonesia, 15227 \\ *Email: adhi.kusnadi@umn.ac.id
}

\begin{abstract}
Abstrak
Pengabdian kepada masyarakat PPK (Program Pengembangan Kewirausahaan) merupakan program pemerintah melalui Hibah PKM (Pengabdian Kepada Masyarakat). Memiliki tujuan membentuk wirausaha baru sehingga dapat membantu meningkatkat jumlah wirausaha di Indonesia. Dengan cara melaksanakan pembinaan kepada usaha rintisan (startup) baru dengan melakukan tahapan pelatihan manajemen kelola usaha dan pelatihan pengetahuan lain untuk membuat wirausaha pemula yang dapat berdiri sendiri berdasarkan ilmu pengetahuan dan teknologi. Kewirausahaan merupakan faktor penting yang dapat membantu meningkatkan ekonomi Indonesia. Total wirausaha Indonesia sekarang ini berjumlah rendah jika dibandingkan dengan negera lain, menempati posisi ke 94 dari 137 negara, salah faktor penyebab adalah pendidikan yang kurang memberikan dorongan pada mahasiswa untuk menjadi entrepreneurship. Universitas Multimedia Nusantara (UMN) berupaya mendidik para mahasiswa untuk siap menjadi wirausaha sejak duduk di bangku kuliah. Salah satunya dengan membuat tech incubator bisnis yaitu Skystar Ventures, yang merupakan inkubator bisnis teknologi terbaik di Indonesia dari KemenristekDikti sejak 2016, member dari Global Accelerator Network, Sillicon Valley dan memiliki akreditasi A. Telah banyak starup yang dihasilkan oleh Skystar. Skystar mengadakan kegiatan rutin untuk menjaring starup baru dengan setiap batch diadakan pendamping selama 6 bulan. Total dari batch satu sampai enam sudah ada 20 tim mahasiswa. Tentu jumlah ini dirasa masih sangat kurang jika dibandingkan dengan kebutuhan jumlah wirausaha yang harus tumbuh untuk mengejar ketertinggalan Indonesia terhadap negara lain. Disinilah dibutuhkan program lain untuk mengoptimalkan potensi yang dimiliki oleh skystar dan mahasiswa. Dengan menjawab permasalahn tersebut diatas diharapkan dapat membantu Indonesia meningkatkan mutu dan jumlah wirausaha baru demi peningkatan perekonomian dan kemandirian Indonesia. Program ini berhasil membentuk usaha rintisan sebanyak 5 buah dengan berbagai bidang kegiatan.
\end{abstract}

Kata kunci: Usaha Rintisan, PPK, incubator, kewirausahaan

\begin{abstract}
PPK (Program Pengembangan Kewirausahaan) is a government program through the Community Service Grant. This program carries out activity for making new startups through business management training and several other creative activities to produce new science and technology independent entrepreneurs. Entrepreneurship is one factor that can drive an increase in the Indonesian economy. The number of entrepreneurs in Indonesia still shows a low percentage when compared to other countries, only ranked 94 out of 137 countries. One cause of the low level of entrepreneurship is the education system that is less encouraging students to develop into an entrepreneurship. Universitas Multimedia Nusantara (UMN) seeks to educate students to be ready to become entrepreneurs since sitting on college benches. One way is by creating a business tech incubator, Skystar Ventures, which has been accredited as the best technology business incubator in Indonesia from KemenristekDikti since 2016, a member of the Global Accelerator Network, Sillicon Valley and has accreditation A. Many startups have been produced by Skystar. Skystar holds regular activities to develop new startups, with each batch taking time 6 months. From batches one to six there were 20 student teams has created. This amount is still considered very less when compared with the needs of the number of entrepreneurs who must grow to catch up with Indonesia against other countries. This is where other programs are needed to optimize the potential of skystar and students. Answering these problems is expected to help Indonesia improve the quality and number of new entrepreneurs for the sake of
\end{abstract}


improving Indonesia's economy and independence. This program has succeeded in forming 5 startups with various fields of activity.

Keywords: startup, PPK, incubator, entrepreneurship

Format Sitasi: Kusnadi, A., Wella, \& Winantyo, R. (2020). Upaya Peningkatan Jumlah Usaha Rintisan melalui Program Pengembangan Kewirausahaan. Jurnal SOLMA. Vol. 09(1): 186-200. Doi: http://dx.doi.org/10.29405/solma.v9i1.4890

\begin{tabular}{l|l|}
\hline Diterima: 10 April 2020 & | Revisi 16 April 2020
\end{tabular}

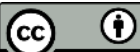

(C) 2020 Oleh authors. Lisensi Jurnal Solma, LPPM-Uhamka, Jakarta. Artikel ini bersifat open access yang didistribusikan di bawah syarat dan ketentuan Creative Commons Attribution (CC BY) license. (http://creativecommons.org/licenses/by/4.0/).

\section{PENDAHULUAN}

Pengabdian kepada masyarakat PPK (Program Pengembangan Kewirausahaan) merupakan program pemerintah melalui Hibah PKM (Pengabdian Kepada Masyarakat) yang setiap tahun diselenggarakan. Program ini melaksanakan pembinaan kepada usaha rintisan (startup) baru dengan mengadakan training manajemen usaha dan pelatihan pengetahuan lain untuk membuat pengusaha muda baru yang dapat berdiri sendiri berdasarkan ilmu pengetahuan dan teknologi. Kewirausahaan merupakan faktor penting yang dapat membantu meningkatkan ekonomi Indonesia Suryadi (2018), karena mampu meningkatkan ide dan kreasinya yang bernilai ekonomi, sehingga masyarakat tidak bergantung lagi kepada pemerintah, dan dapat menarik investasi asing untuk berinvestasi di Indonesia.

Wirausaha pada saat ini masih memiliki jumlah kecil di Indonesia Rahim and Basir (2019). Menteri Perdagangan Enggartiasto Lukita dalam Harian Republika pada oktober 2018, mengatakan tingkat kewirausahaan Indonesia menempati posisi 94 dari 137 negara Zuraya (2018) Husna and Magelang (2019). Tahun 2018, di negara maju rata-rata 14 persen dari total penduduk usia produktif adalah wirausaha, Indonesia hanya 3,1 persen Ariyanto (2019). Global Enterpreneurship Index dalam laporannya menyatakan, negaranegara maju seperti Amerika Serikat, Swiss, Kanada, dan Inggris berada pada posisi sepuluh besar. Dari Asia, Hong Kong dan Taiwan menempati posisi 13 dan 18. Peringkat Indonesia berada di bawah negara-negara ASEAN seperi Singapura, Malaysia, Thailand, dan Filipina yang masing-masing menduduki posisi 27, 58, 71, dan 84 Baumol (2018). Menurutnya juga faktor utamanya yakni pendidikan yang tidak maksimal mendorong mahasiswa untuk berkeinginan menjadi wirausaha. Wirausahawan masih dilihat kurang 
prestise oleh masyarakat, dan memerlukan waktu relative lama untuk sukses. Sebab itu UMN sebagai salah satu universitas swasta yang utama di Indonesia ikut mendorong mahasiswa berkembang menjadi entrepreneur. Perguruan tinggi memiliki peranan penting dalam menciptakan lulusan yang mampu berdaya saing terutama dalam membangun ekonomi bangsa (Hasdar, Fera, and Syaifulloh 2019).

Universitas Multimedia Nusantara (UMN) berupaya mendidik para mahasiswa untuk siap menjadi wirausaha sejak duduk di bangku berkuliah. Salah satunya dengan membuat tech incubator bisnis yaitu Skystar Ventures, sebagai inkubator bisnis teknologi terbaik di Indonesia oleh KemenristekDikti sejak 2016, member Global Accelerator Network, Sillicon Valley dan terakreditasi A (skystar 2018). Telah banyak starup yang dihasilkan, sebagai contoh mahasiswa Informatika UMN Muhammad Geza mengembangkan usaha cemilan yang bernama Snacksnake.id. Awalnya, Geza berinisiatif berjualan kerupuk atau ciki di SMA. Kemudian ia membuka brand di UMN dengan produk lidi-lidian, basreng (bakso goreng), makaroni kering, dan lainnya. Kemudian mahasiswi Strategic Communication UMN Victoria Trifena memilih bidang branding dan graphic design, seperti jasa pembuatan desain CV, baliho, flyer, menu, hingga kartu nama. Ada lagi Walibu, fokus pada pengembangan kerajinan tangan Noken dari Papua menjadi startup pertama yang melanjutkan pengembangan bisnisnya ke program Rise.Inc dari Akselerator Instellar Indonesia. Skystar mengadakan kegiatan rutin untuk menjaring startup baru dengan setiap batch diadakan pendamping selama 6 bulan. Total dari batch satu sampai enam itu ada 20 tim mahasiswa. Tentu jumlah ini dirasa masih sangat kurang jika dibandingkan dengan kebutuhan jumlah wirausaha yang harus tumbuh untuk mengejar ketertinggalan Indonesia terhadap negara lain. Disinilah dibutuhkan program lain untuk mengoptimalkan potensi yang dimiliki oleh skystar dan mahasiswa. Dari hasil survey internal yang dilakukan, mahasiswa kurang mengetahui potensi yang dimiliki oleh Skystar dan potensi yang dimiliki oleh diri mereka sendiri. Di era disrupsi ekonomi yang sedang terjadi di Indonesia, banyak perusahaan rintisan alias startup yang lahir dan bersaing satu sama lain. Pertumbuhan bisnis Startup di Indonesia berkembang baik dan menggembirakan. Setiap bulan Startup baru bermunculan. Menurut dailysocial.net, terdapat kurang lebih 1500 Startup lokal yang ada di Indonesia (Haikal 2017). Dengan adanya program ini, mutu dan jumlah wirausaha mandiri di Indonesia dapat meningkat. Pengabdian Kepada Masyarakat ini meiliki tujuan utama untuk menghasilkan wirausaha baru yang mandiri, selain itu diharapkan dapat: 
1. Menerapkan sebuah pemahaman dasar mengenai jiwa seorang wirausaha berbasis teknologi.

2. Menjembatani para tenant muda dengan perusahaan-perusahaan multinasional yang dapat dijadikan sebagai investor maupun best practice mereka.

3. Mengimplementasikan produk / jasa bernilai bisnis dan berbasis teknologi yang mampu berkompetisi.

\section{MASALAH}

Berdasarkan penjelasan latar belakang pada bab sebelumnya timbul permasalahan yang dihadapi pada program pengembangan kewirausahaan Universitas Multimedia Nusantara adalah sebagai berikut:

1. Bagaimana membangun wirausaha baru yang jiwa wirausaha sejak dini.

2. Bagaimana membangun kerjasama dengan inkubator bisnis bereputasi, Skystar Venture dalam pengelolaan knowledge kewirausahaan.

3. Bagaimana mengimplementasikan produk / jasa bernilai bisnis dan berbasis teknologi yang dapat berkompetisi.

Dengan menjawab permasalahn tersebut diatas diharapkan dapat membantu Indonesia meningkatkan mutu dan jumlah wirausaha baru demi peningkatan perekonomian dan kemandirian Indonesia. Dengan target capaian sebanyak 5 starup baru persetiap kegiatan.

\section{METODE PELAKSANAAN}

\section{Pola Rekuitment}

Cara penjaringan calon peserta pelatihan program PPK, diawali dengan rekrutmen tenant, dilakukan secara berkala dengan periode setiap tahun dengan menpersiapkan boot camp dengan maksud menumbuhkan jiwa dan ide kewirausahaan peserta. Acara Boot camp dihadiri oleh para pendiri startup yang telah berhasil. Tujuan dari kegiatan ini adalah menjaring sebanyak banyaknya peserta yang mempunyai proposal pendirian startup. Pada tahun bertama berhasil dijaring 30 mahasiswa dengan 6 proposal. Lebih banyak dari target akhir sebanyak 4 wirausaha baru. Dilanjutkan dengan melakukan seleksi peserta. Kegiatan ini dilakukan secara bertahap, dengan tahapan:

1. Memperkenalkan kegiatan PPK kepada stakeholder antara lain ketua jurusan, mahasiswa, dan alumni. 
2. Melakukan pemilihan calon peserta.

3. Menseleksi 30 peserta yang telah lolos dari tahapan sebelumnya dan dinyatakan berhak melanjutkan program. Kemudian diseleksi kembali sebanyak 20 peserta dengan nilai terbaik, yang akan mengikuti program PPK. Kemudian peserta bekali keahlian pembentukan kapasitas startup dengan target 5 sampai 8 peserta wirausaha baru per tahun yang dapat berdiri sendiri. Cara penjaringan peserta/tenant dijelaskan pada Gambar 1.

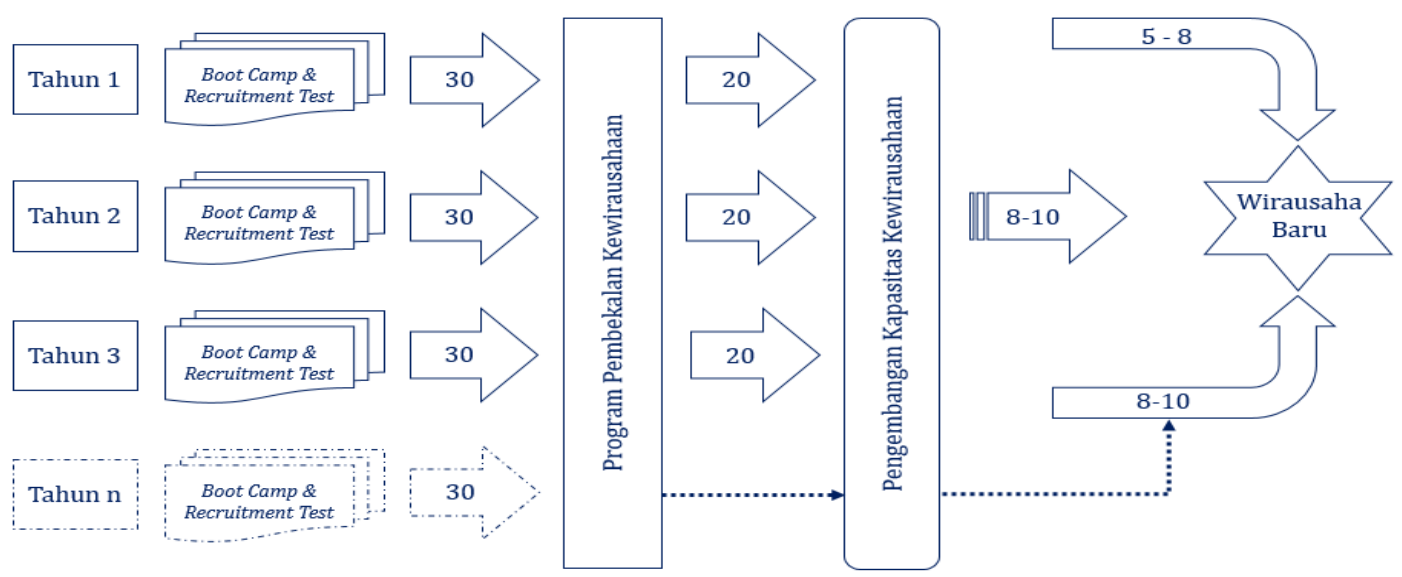

Gambar 1. Pola Rekuitment

\section{Pola Pendekatan}

Secara garis besar cara pendekatan yang dilakukan digambarkan di Gambar 2 berikut ini.

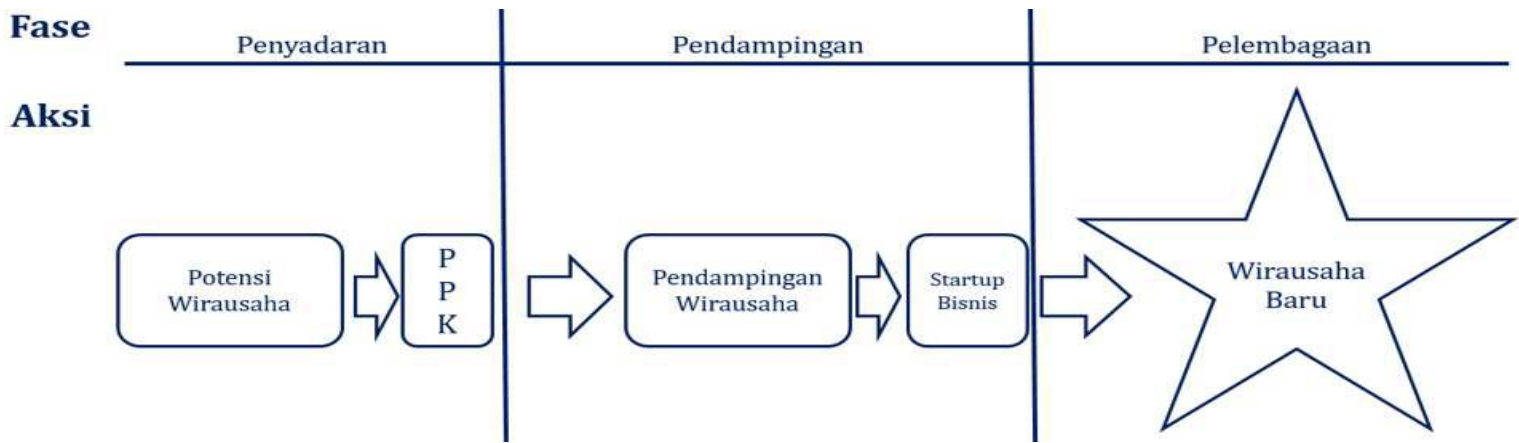

Gambar 2. Metode Pendekatan PPK 
1. Fase Penyadaran Kewirausahaan, fase penyadaran memiliki target membangun jiwa 'enterprenuer' yang akan melahirkan kreatifitas dan proaktif pada situasi lingkungan (Fadillah 2015). Pada tahun pertama, 20 mahasiswa dengan 4 proposal mengikuti kegiatan boot camp, diisi oleh successor founder startup, contoh kasus, diskusi, dan simulasi. Kegiatan ini dilanjutkan mentoring dan magang pada starup yang sudah berhasil. Pelatihan dilakukan dengan praktek langsung, dengan menimba ilmu secara actual (Winantyo, Kusnadi, and Wella 2018). Diharapkan kegiatan ini berlanjut pada tahun berikut dengan membangun 4 startup baru dan monitoring, pendampingan pada peserta sebelumnya agar dapat mandiri.

2. Tahapan kedua ini memiliki agenda membimbing peserta menyusun manajemen dan produksi, juga mencari solusi atas masalah yang berkaitan dengan kegiatan usaha. Bantuan dalam bentuk bimbingan yang dilakukan secara terus berkelanjutan dengan prinsip manajemen kewirausahaan (Cahyani, Timan, and Sultoni 2019) (Mahfud 2013). Lembaga yang telah menjadi rekanan dalam pembinaan dan pembimbingan usaha antara lain: Skystar Ventures, Techinasia, Microsoft Bizspark, Kompas Gramedia, Kompas.com, Startupbisnis.com, dan Awsactive. Pembimbingan Pasar juga merupakan salah satu fase pendampingan, bertujuan menganalisis peluang dan potensi pasar dalam rangka penciptaan dan pengambangan usaha bagi tenant. Pembimbingan pangsa pasar juga dilakukan dengan cara menperkenalkan para wirausaha muda kepada pengusaha sejenis.

4. Fase Pelembagaan Kewirausahaan. Fase akhir ini memiliki target membangun kerja sama antar Universitas Multimedia Nusantara dengan Tenant dan Lembaga mitra, sehingga dapat memanfaatkan keunggulan dari lembaga mitra (Budiyanto et al. 2017) (Budiyanto and Rofieq 2017) (Budiyanto 2016). Target lain yaitu monitoring pengelolaan usaha dari startup yang terbentuk, seperti bimbingan dalam pembuatan badan hukum (PT, CV, UD), perijinan usaha (SIUP, NPWP, TDP), dan lain-lain.

\section{Kolaborasi dengan Lembaga Sejenis di Luar Kampus dan Pola Operasinya}

Kerjasama dengan institusi diluar kampus dilakukan bertujuan membentuk jaringan usaha dan jaringan:

1. Skystar Ventures, menjadi inkubator bisnis yang menyediakan mentor yang berpengalaman dan infrastruktur yang baik demi memfasilitasi para PKMK. 
2. Techinasia, menyediakan mentor/narasumber yang berpengalaman khususnya di bidang pemasaran, marketing, teknologi informasi dan komunikasi, dll.

3. Microsoft Bizspark, menyediakan mentor/narasumber yang berpengalaman khususnya di bidang teknologi informasi dan komunikasi, pemasaran, dll.

4. Kompas Gramedia, menyediakan mentor/narasumber yang berpengalaman khususnya di bidang teknologi informasi dan komunikasi, pemasaran, dll.

\section{HASIL DAN PEMBAHASAN}

Kegiatan pengabdian dimulai dengan mengadakan lomba business plan pada bulan Desember 2017, berkolaborasi dengan departemen Student Development. Student Development menyediakan sarana dan prasarana keberlangsungan lomba. Informasi lomba disebarluaskan melalui jejaring sosial yang dimiliki oleh Universitas Multimedia Nusantara. Terdapat 27 tim yang mengumpulkan proposal ide bisnis. Penyaringan proposal ide bisnis tersebut dibantu oleh pihak Skystar. Mereka memiliki kriteria-kriteria khusus dalam melakukan penyaringan proposal ide bisnis yang telah masuk. Setelah dilakukan penyaringan secara ketat, didapatlah 15 proposal ide bisnis yang masuk ke babak final. Di babak final, 15 tim yang terpilih melakukan presentasi secara tertutup. Namun dari 15 tim yang masuk babak final, 2 diantaranya tidak hadir maka didiskualifikasi. Adapun teknis presentasi adalah 20 menit presentasi dan 10 menit tanya jawab. Penjurian dilakukan oleh tim PPK, yaitu Bpk Adhi Kusnadi, Bpk Rangga Winantyo, dan Bu Wella. Pada presentasi final didapat 5 pemenang yang akan dibimbing dalam Program Pengembangan Kewirausahaan (PPK) berkolaborasi dengan Skystar. Adapun kelima kelompok tersebut antara lain: Kopilembur, Jusin.id, Lamina, Urganizer, dan Tempel.in.

\section{Kopilembur}

Kopilembur adalah nama dari dari starup ini dan sudah mendapatkan sertifikat HAKI, latar belakang pembuatannya adalah para mahasiswa dan pekerja tidak dapat terhindar dari suntuk, galau, resah, dan gelisah dan tidak ada kesempatan untuk membeli kopi di coffee shop atau tempat lain yang memerlukan waktu. Oleh karena itu, Kopilembur diperuntukan bagi segala kalangan untuk menikmati kopi yang segar dan alami, menemani di segala kesibukan aktivitas tanpa harus mendatangi pedagang, dapat membeli melalui smartphone (Wella et al. 2018). Gambar 3 merupakan tampilan aplikasi kopilembur. 


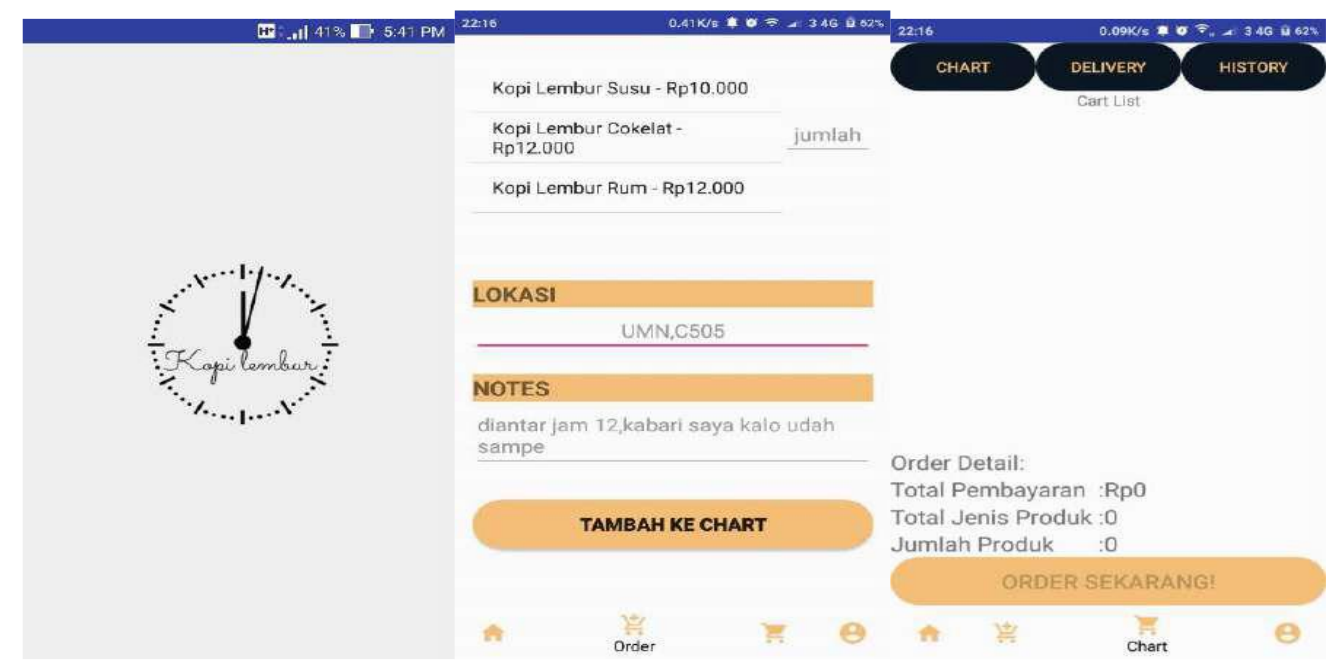

Gambar 3. Tampilan Aplikasi Kopilembur

\section{Jusin.id}

Jusin.id merupakan jenis usaha yang bernaung di dunia minuman sama dengan Kopilembur. Foku pada penjualan jus asli tanpa tambahan zat ilmiah, murah untuk segala kalangan dan gratis biaya antar serta mementingkan rasa dan kualitas yang cocok di kantong terutama untuk para mahasiswa. Target utama Jusin.id adalah mahasiswa dan seluruh masyarakat di sekitar kampus, dengan harapan bahwa dapat membawa serta menjaga kesehatan tanpa harus mengeluarkan biaya yang mahal. Adapun traksaksi jual beli jus ini dapat dilakukan melalui jejaring internet. Para pelanggan bisa mengakses aneka rasa yang ditawarkan lewat jusin.online.

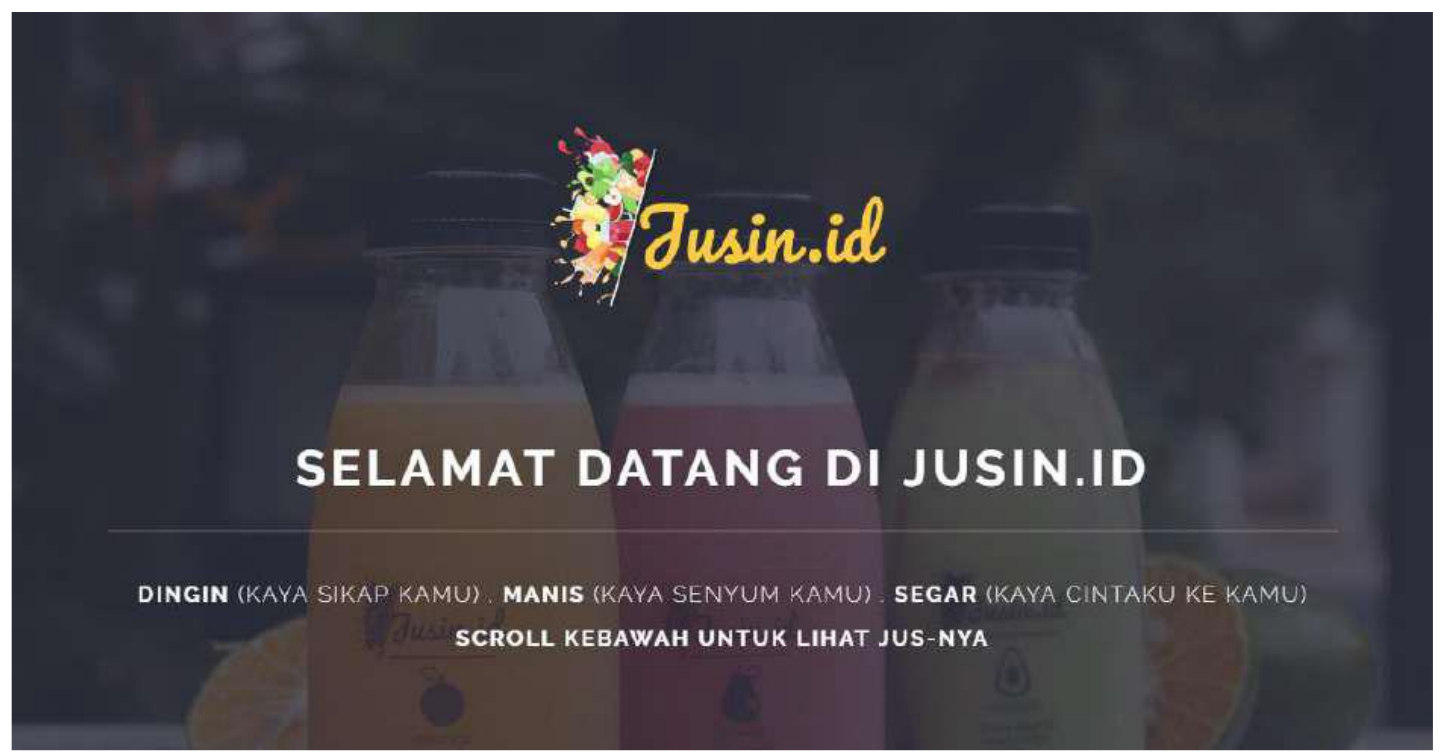

Gambar 4. Halaman Utama Jusin.id 


\section{Lamina}

Lamina merupakan aplikasi pencatatan keuangan pribadi yang menggunakan metode gamifikasi. Secara umum Lamina berfungsi untuk mencatat maupun melihat pengeluaran dan pemasukan pribadi dengan basis Android baik dalam bentuk daftar maupun statistik. Dengan menggunakan aplikasi ini, user dapat melakukan pencatatan keuangan pada tanggal tersebut maupun tanggal yang sudah terlewati. Tindakan tersebut memicu untuk menambahkan coin yang dimiliki user dengan jumlah coin sesuai level yang dimiliki. Semakin tinggi level maka semakin tinggi coin yang didapatkan user di setiap input-an pengeluaran maupun pemasukannya. User juga dapat melakukan edit maupun delete terhadap pengeluaran dan pemasukan yang telah dilakukan user. Adanya batas maksimum penambahan coin per hari yang dipicu dengan input-an user merupakan bentuk pencegahan kecurangan yang mungkin saja dilakukan. Coin tersebut dapat digunakan user untuk membeli ruangan yang dapat membuat tower menjadi semakin tinggi dan juga membeli barang-barang yang berguna untuk melengkapi dekorasi di setiap ruangannya. User dapat mempekerjakan NPC yang berjalan di depan tower pada ruangan yang telah memiliki furniture yang lengkap. Hal ini berguna untuk menambahkan coin yang dimiliki user disetiap periode waktu tertentu sesuai dengan jenis ruangan yang dimiliki user.

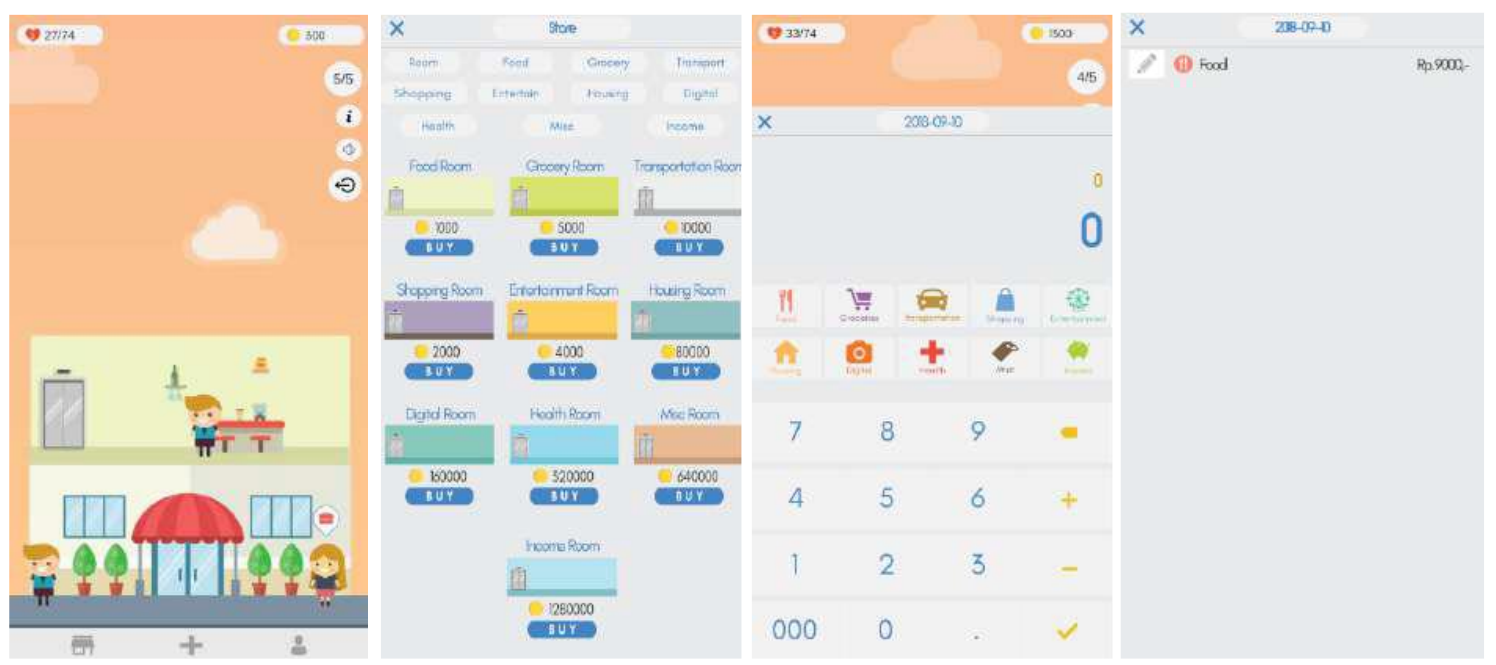

Gambar 5. Tampilan Aplikasi Lamina

\section{Urganizer}

Urganizer adalah sebuah website yang mempertemukan antara pengguna dan penyedia jasaevent organizer. Kata Urganizer sendiri diambil dari kata organizer yang merupakan layanan yang diangkat menjadi topik utama website ini. Ditambah kata U pada 
depan kata yang dalam bahasa inggris merupakan singkatan dari kata you yang berarti kamu/Anda. Dalam hal ini, website menjadi jembatan penghubung antara orang yang membutuhkan layanan organizer dengan vendor organizer.

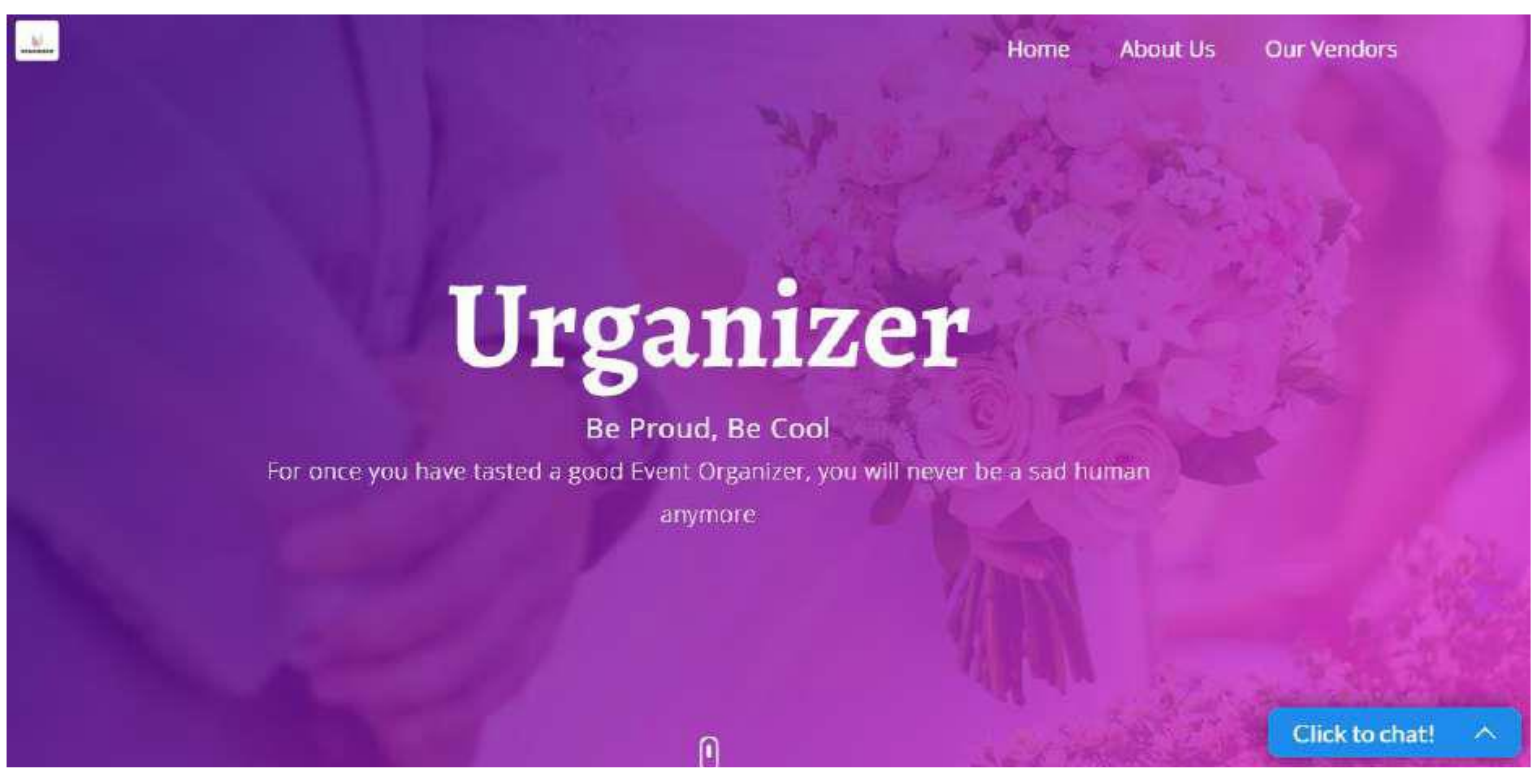

Gambar 6. Halaman Utama Urganizer

Fitur yang disediakan antara lain signup member/vendor, login member/vendor, file upload, send e-mail, layanan pelanggan serta rating vendor. Pengguna yang memungkinkan untuk Urganizer adalah individu-individu yang mencari event organizer untuk kebutuhan acaranya dan badan usaha atau individu yang telah berizin untuk memasarkan jasanya pada website

Urganizer.

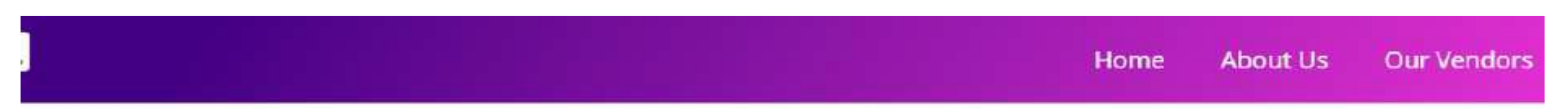

\section{Our Value}

Preparing For A Better You
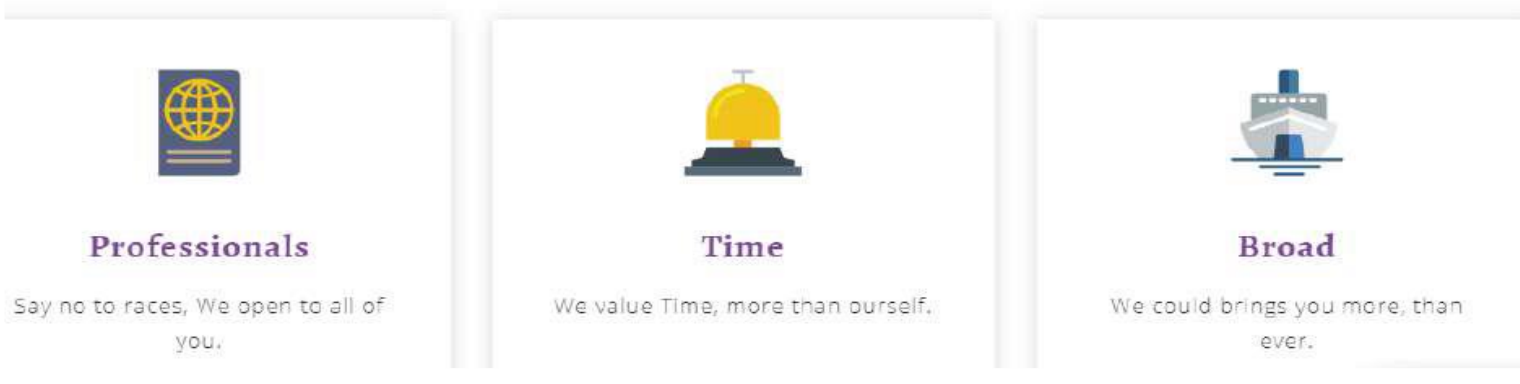

Gambar 7. Halaman Nilai-nilai Urganizer 
Keunggulan apabila menggunakan website Urganizer adalah dapat menemukan penyedia jasa yang berizin resmi dan memiliki rating. Apabila rating-nya bagus tentu akan semakin terpercaya begitu juga sebaliknya.

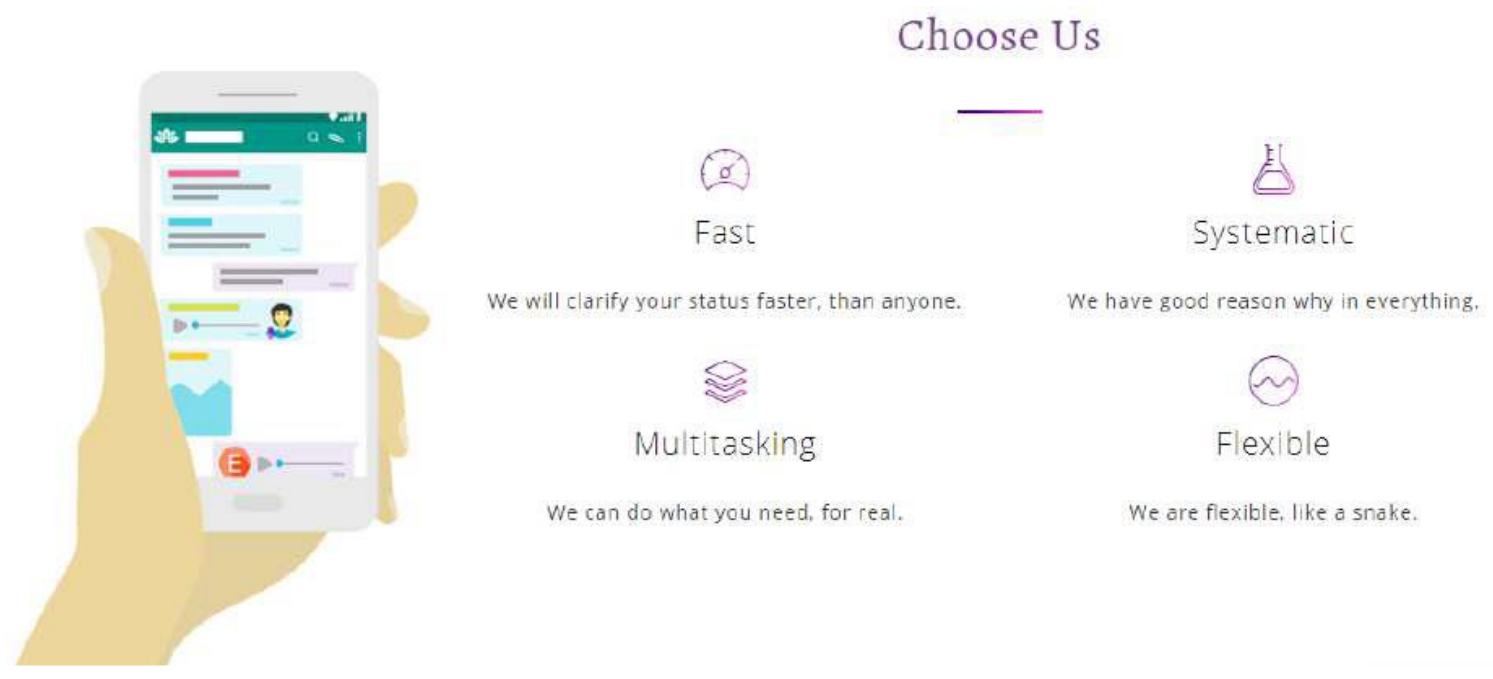

Gambar 8. Halaman Kelebihan Urganizer

\section{Tempel.in}

Ide bisnis yang dimiliki yaitu car advertising. Ide bisnis car advertising ini diberi nama/merk Tempel.in, dengan tagline yang diusung adalah: Download, Tempel, Duit (Do it). Tagline ini bertujuan untuk memvisualisasikan proses kerja ketika menjadi mitra dari Tempel.in, prosesyang akan dilalui semudah seperti men-download aplikasi, menempel iklan, dan mendapatkan keuntungan. Adapun keunikan dari Tempel.in dengan merk car advertising yang sudah ada adalah memfokuskan kepada UKM (Usaha Kecil dan Menengah) di suatu daerah, yang merasa kesulitan dalam melakukan iklan (konvensional dan digital) dikarenakan faktor teknis maupun faktor ekonomi. Selain itu, Tempel.in juga menyediakan jasa konsultasi desain iklan yang efektif. Hal ini bertujuan untuk membantu mempermudah para UKM dalam mendesain iklan, dimana mereka tidak memiliki keahlian tersebut. Kemacetan yang tak kunjung hilang di perkotaan Indonesia memberikan kesempatan bagi Tempel.in dalam memperluas bisnis. Memanfaatkan kondisi negatif perkotaan tersebut untuk meningkatkan kesejahteraan dan kebahagiaan masyarakat Indonesia. Selain itu, membantu para pelaku UKM dalam memasarkan produk/jasa yang mereka tawarkan. Membantu mempromosikan dan memperkenalkan produk dan jasa dari para UKM. 


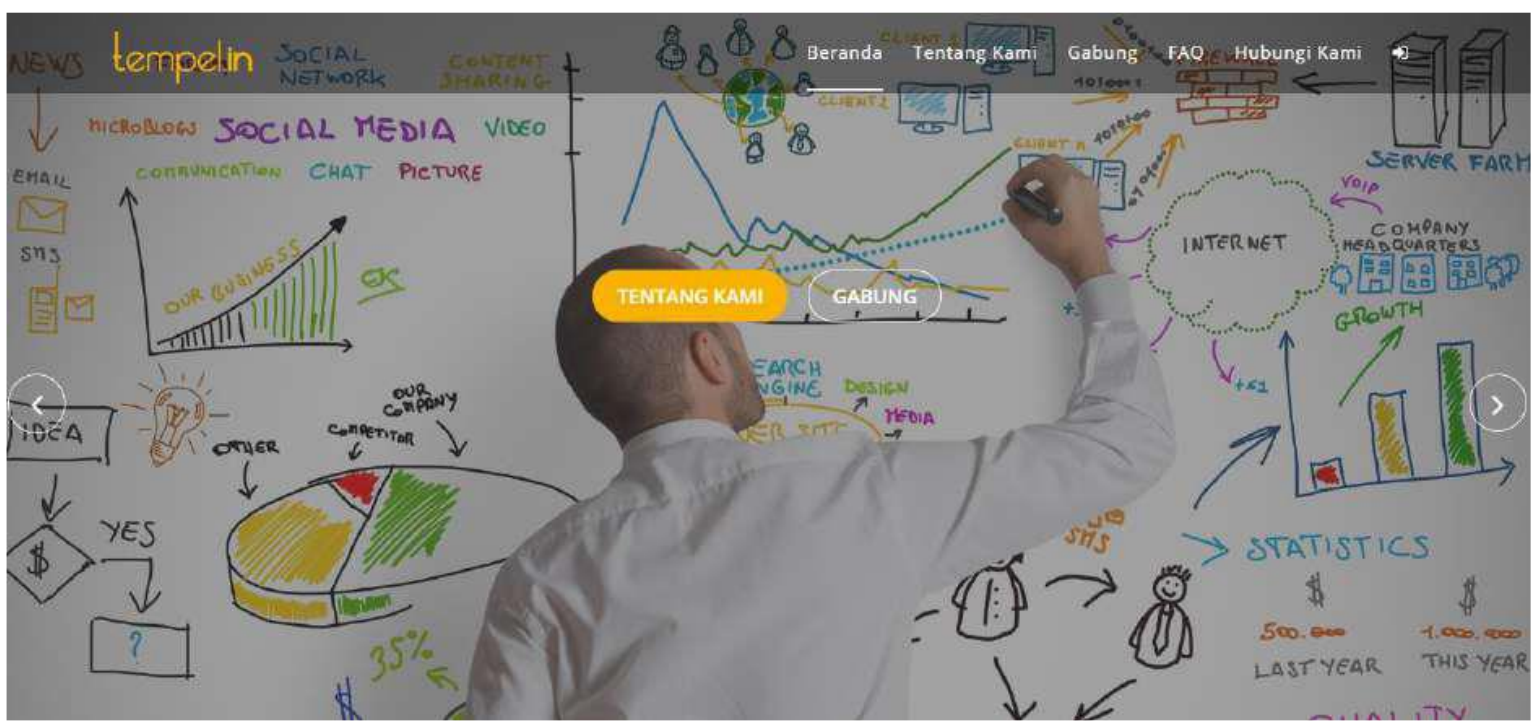

Gambar 9. Halaman Awal Tempe.in

Dari kelima starup yang telah berhasil dibuat dapat diambil beberapa point secara keseluruhan yaitu:

A. Permasalahan

- Starup berhasil dibuat tetapi sulit berkembang, walaupun ada dua starup yang berhasil mencatat transaksi dan mendapatkan keuntungan, yaitu Kopilembur dan Jusin.id. Tetapi kedua starup itu pun tidak berkembang meningkat.

- Keterbatasan waktu pengelolaan bisnis, karena pengelola masih berstatus mahasiswa yang masih harus hadir dikelas dan melakukan kegiatan perkuliahan lainnya.

- Jangkuan bisnis yang masih terbatas di sekitar UMN, karena kemampuan pengelola dan keterbatasn promosi.

B. Solusi

- Pendampingan secara simultan oleh skystar sampai bisa berdiri mandiri

- Investasi, sehingga starup dapat dikelola secara professional tidak dikelola disela sela waktu luang perkuliahan dengan membayar pegawai.

- Biaya investasi dapat digunakan juga untuk biaya promosi sehingga jangkauan semakin luas sehingga dapat menambah jumlah transaksi. 


\section{Peluang}

Melihat keberhasilan dua starup menghasilkan keuntungan, ada peluang besar untuk mengembangkan kelima starup yang telah berhasil dibuat dan membangun starup baru. Dengan cacatatan solusi yang diusulkan dapat dilakukan. Memang tidak mudah, akan tetapi dengan dukungan semua stakeholder, dipercaya program PKK ini dapat berhasil. Secara rekapitulasi perbandingan kelima startup dapat dilihat pada tabel 1

Tabel 1. Data Ringkasan Perbandingan Startup

\begin{tabular}{|c|c|c|c|c|c|c|}
\hline No & & Kopilembur & Jusin.id & Lamina & Urganizer & Tempel.in \\
\hline 1. & Jenis Usaha & Minuman & Minuman & $\begin{array}{l}\text { Software } \\
\text { Keuangan }\end{array}$ & $\begin{array}{l}\text { Event } \\
\text { Organizer }\end{array}$ & $\begin{array}{l}\text { Car } \\
\text { Advertising }\end{array}$ \\
\hline 2. & Permasalahan & $\begin{array}{l}\text { Perkembang } \\
\text { stagnan. }\end{array}$ & $\begin{array}{l}\text { Perkembang } \\
\text { stagnan }\end{array}$ & $\begin{array}{l}\text { Tidak } \\
\text { Berkembang }\end{array}$ & $\begin{array}{l}\text { Tidak } \\
\text { Berkembang }\end{array}$ & $\begin{array}{l}\text { Tidak } \\
\text { Berkembang }\end{array}$ \\
\hline \multirow[t]{2}{*}{3.} & $\begin{array}{l}\text { Keterbatasan } \\
\text { dan } \\
\text { Keterbatasan }\end{array}$ & $\begin{array}{l}\text { Waktu } \\
\text { terbatas, } \\
\text { dikelola } \\
\text { sambal kuliah }\end{array}$ & $\begin{array}{l}\text { Waktu } \\
\text { terbatas, } \\
\text { dikelola } \\
\text { sambal kuliah }\end{array}$ & $\begin{array}{l}\text { Hasil belum } \\
\text { teruji, } \\
\text { pembuat } \\
\text { bukan ahli } \\
\text { keuangan }\end{array}$ & $\begin{array}{l}\text { Tidak } \\
\text { dilanjutkan } \\
\text { pada versi } \\
\text { advance }\end{array}$ & $\begin{array}{l}\text { Tidak } \\
\text { dilanjutkan } \\
\text { pada versi } \\
\text { advance }\end{array}$ \\
\hline & & $\begin{array}{l}\text { Kadang tidak } \\
\text { bisa } \\
\text { mengirim } \\
\text { pesanan } \\
\text { secara cepat }\end{array}$ & $\begin{array}{l}\text { Kadang tidak } \\
\text { bisa } \\
\text { mengirim } \\
\text { pesanan } \\
\text { secara cepat }\end{array}$ & $\begin{array}{l}\text { Belum } \\
\text { dilanjut } \\
\text { sampai } \\
\text { sekala bisnis }\end{array}$ & $\begin{array}{l}\text { Belum } \\
\text { dilanjut } \\
\text { sampai } \\
\text { sekala bisnis }\end{array}$ & $\begin{array}{l}\text { Belum } \\
\text { dilanjut } \\
\text { sampai sekala } \\
\text { bisnis }\end{array}$ \\
\hline & Kelebihan & $\begin{array}{l}\text { Secara } \\
\text { prospek } \\
\text { bisnis } \\
\text { menjanjikan }\end{array}$ & $\begin{array}{l}\text { Secara } \\
\text { prospek } \\
\text { bisnis } \\
\text { menjanjikan }\end{array}$ & $\begin{array}{l}\text { Secara } \\
\text { prospek } \\
\text { bisnis } \\
\text { menjanjikan }\end{array}$ & $\begin{array}{l}\text { Secara } \\
\text { prospek } \\
\text { bisnis } \\
\text { menjanjikan } \\
\end{array}$ & $\begin{array}{l}\text { Secara } \\
\text { prospek } \\
\text { bisnis } \\
\text { menjanjikan }\end{array}$ \\
\hline & Solusi & $\begin{array}{l}\text { Dikelola full } \\
\text { Time dan } \\
\text { Investor }\end{array}$ & $\begin{array}{l}\text { Dikelola full } \\
\text { Time dan } \\
\text { Investor }\end{array}$ & $\begin{array}{l}\text { Dikelola full } \\
\text { Time dan } \\
\text { Investor }\end{array}$ & $\begin{array}{l}\text { Dikelola full } \\
\text { Time dan } \\
\text { Investor }\end{array}$ & $\begin{array}{l}\text { Dikelola full } \\
\text { Time dan } \\
\text { Investor }\end{array}$ \\
\hline
\end{tabular}

\section{KESIMPULAN}

Pengabdian ini telah berhasil melahirkan 5 kelompok wirausaha yang beranggotakan Mahasiswa Universitas Multimedia Nusantara dari berbagai program studi. Adapun kelima kelompok tersebut antara lain: Kopilembur, Jusin.id, Lamina, Urganizer, dan Tempel.in. Kelima kelompok wirausaha tersebut memiliki fokus market yang berbeda-beda. Dua kelompok wirausaha berfokus kepada kuliner, yaitu produk minuman. Lalu tiga kelompok lainnya menyediakan jasa. Jasa yang ditawarkan oleh ketiga kelompok wirausaha tersebut adalah jasa keuangan, jasa event organizer, dan jasa periklanan. Terdapat satu merk dagang yang telah di-HAKI-kan yaitu kelompok wirausaha Kopilembur. Dimana keempat lainnya akan segera menyusul di tahun pengabdian ini. Telah terbangun kerjasama dengan 
inkubator bisnis Skystar Venture dengan rencana program sejenis tahun berikutnya dan melakukan pendampingan agar produk dapat tetap dapat berkompetisi.

\section{UCAPAN TERIMA KASIH}

Ucapan terima kasih kepada Universitas Mutimedia Nusantara atas fasiltas yang telah disediakan, KemeristekDikti atas Hibah PPK dan para mahasiswa yang telah mengikuti kegiatan PKM ini.

\section{DAFTAR PUSTAKA}

Ariyanto, Adi. 2019. "Sociopreneur Dan Peran Kita Di Masyarakat - LPM Journal." Lpmjpurnal.Id. May 1, 2019. https://www.lpmjournal.id/sociopreneur-dan-perankita-di-masyarakat-940/.

Baumol, William. 2018. "Global Entrepreneurship Index | Global Entrepreneurship Development Institute." Global Entrepreneurship Index. 2018. https://thegedi.org/global-entrepreneurship-and-development-index/.

Budiyanto, Hery (Universitas Merdeka Malang). 2016. "Menumbuhkembangkan Wirausaha Mahasiswa Dan Alumni Melalui Program Iptek Bagi Kewirausahaan." Jurnal ABDI $M \quad A S \quad$ Unmer Malang $1 \quad$ (1): 18-24. http://jurnal.unmer.ac.id/index.php/jpkm/article/view/1169/796.

Budiyanto, Hery, Universitas Merdeka Malang, Agus Suprapto, Universitas Merdeka Malang, Dina Poerwoningsih, and Universitas Merdeka Malang. 2017. "Program Pengembangan Kewirausahaan Dalam Bentuk Inkubator." Seminar Nasional Sistem Informasi, no. September: 385-94.

Budiyanto, Hery, and Mochammad Rofieq. 2017. "Menumbuhkembangkan Wirausaha Mahasiswa Dan Alumni Melalui Program Iptek Bagi Kewirausahaan Di Universitas Merdeka Malang." Jurnal Pengabdian Masyarakat Universitas Merdeka Malang 1 (1). https://doi.org/10.26905/abdimas.v1i1.1169.

Cahyani, Sinta Septia Anggra, Agus Timan, and Sultoni Sultoni. 2019. "Manajemen Pelatihan Kewirausahaan Bagi Peserta Didik Di Kampoeng Kidz." Jurnal Administrasi Dan Manajemen Pendidikan 2 (1): 001-009. https://doi.org/10.17977/um027v2i22019p1.

Fadillah, Nur. 2015. "Menumbuhkan Jiwa Entrepreneurship Muslim Yang Sukses.” Eksis X (1): 81-94. http://ejournal.stiedewantara.ac.id.

Haikal, Moch Fachri. 2017. "EVALUASI BUSINESS MODEL CANVAS TERHADAP BISNIS START-UP (STUDI KASUS PADA PERUSAHAAN PT. SOLUSI HIJAU INDONESIA).” Universitas Telkom.

Hasdar, Muhamad, Melly Fera, and Muhammad Syaifulloh. 2019. "Pemberdayaan Kelompok Bisnis Mahasiswa Berbasis IPTEK Melalui Program Agrofood Technopreneur." SOLMA 8 https://journal.uhamka.ac.id/index.php/solma/issue/view/127/PDF. 
Husna, Aftina, and Universitas Muhammadiyah Magelang. 2019. "Karakter Wirausaha Sebagai Anteseden Efikasi Diri Dan Intensi Berwirausaha Pada Mahasiswa," no. September: 29-36.

Mahfud, Tuatul. 2013. "Praksis Pembelajaran Kewirausahaan Pada Unit Produksi Jasa Boga.” Jurnal Pendidikan Vokasi 2 (1): 27-40. https://doi.org/10.21831/jpv.v2i1.1014.

Rahim, Abd Rahman, and Basir Basir. 2019. "Peran Kewirausahaan Dalam Membangun Ketahanan Ekonomi Bangsa.” Economic Resources Journal s Vol. 2 N (1): 36.

skystar, ventures. 2018. "Skystar Ventures Tech Incubator UMN Raih Pendanaan BPKIBT Dan PPBT Senilai Ratusan Juta Rupiah Dari Kemenristekdikti - UMN." Https://Www.Umn.Ac.Id/. 2018. https://www.umn.ac.id/skystar-ventures-techincubator-umn-raih-pendanaan-bpkibt-dan-ppbt-senilai-ratusan-juta-rupiah-darikemenristekdikti/.

Suryadi, Dedy. 2018. "Peran Dan Strategi Perkembangan Kewirausahaan Dan Tantangannya Dalam Menghadapi Perekonomian Di Masa Yang Akan Datang." Jurnal Universitas Bale Bandung, no. April: 1-14.

Wella, W, R Winantyo, B Pratama, A Kusnadi, R B Hidayat, and A S Thidar. 2018. "Is Startup Business on Coffee Usable with Mobile Application?" In 2018 Joint 10th International Conference on Soft Computing and Intelligent Systems (SCIS) and 19th International Symposium on Advanced Intelligent Systems (ISIS), 1271-76. https://doi.org/10.1109/SCIS-ISIS.2018.00199.

Winantyo, R, A Kusnadi, and W Wella. 2018. "Building Entrepreneurship Spirit for University Student through Entrepreneurs Training Program.” In 2018 Joint 10th International Conference on Soft Computing and Intelligent Systems (SCIS) and 19th International Symposium on Advanced Intelligent Systems (ISIS), 762-66. https://doi.org/10.1109/SCIS-ISIS.2018.00127.

Zuraya, Nidia. 2018. "Enggartiasto: Tingkat Kewirausahaan Di Indonesia Rendah | Republika Online.” Republika.Co.Id. October 18, 2018. https://www.republika.co.id/berita/ekonomi/korporasi/18/10/18/pgsax3383enggartiasto-tingkat-kewirausahaan-di-indonesia-rendah. 